M. REYNDERS, B. S. MATSUURA, M. BÉROUTI, D. SIMONESCHI, A. MARZIO,

M. PAGANO*, D. TRAUNER* (NEW YORK UNIVERSITY, USA)

PHOTACs Enable Optical Control of Protein Degradation

Sci. Adv. 2020, 6, DOI: 10.1126/sciadv.aay5064.

\title{
PHOTACs Enable Optical Control of Protein Degradation
}
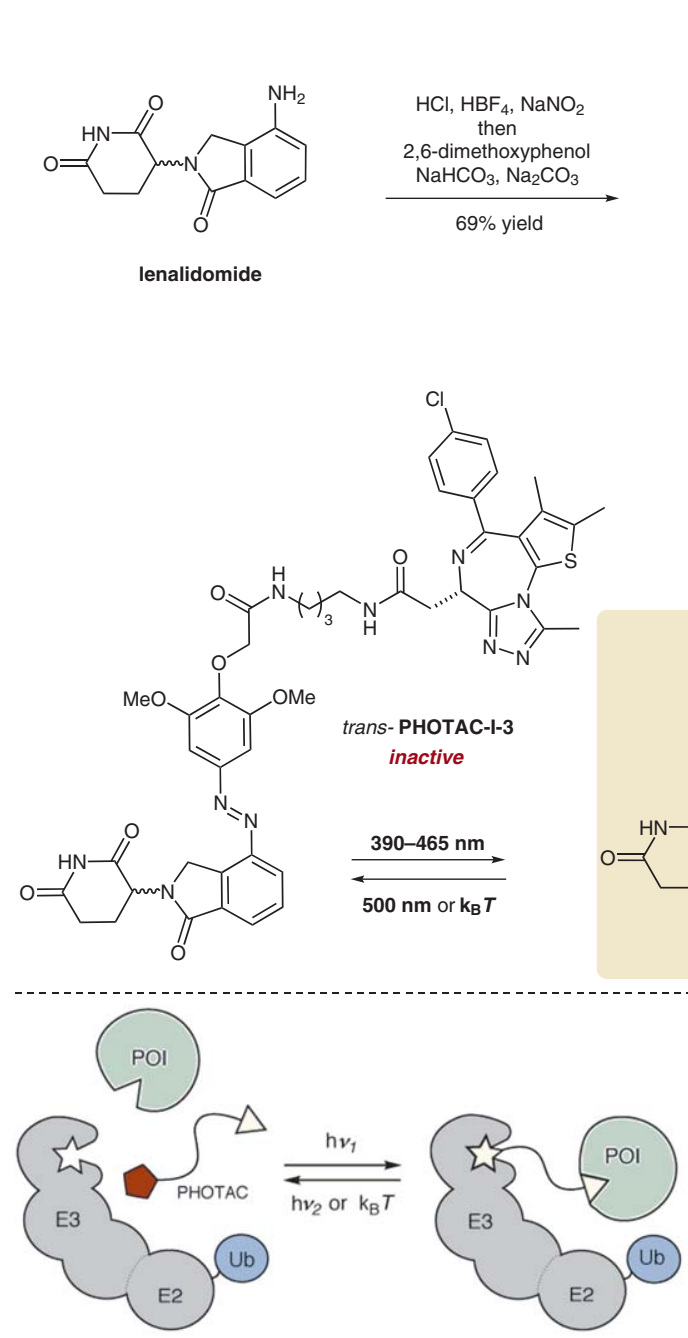

ubiquitylation

Significance: PROTACs (PROteolysis TArgeting Chimeras) have emerged as a new modality in pharmacology (Sakamoto et al. PNAS 2001, 98, 8554), but their catalytic mechanism of action poses risks. PHOTACs (PHOtochemically TArgeting Chimeras) can be spatiotemporally controlled for precise and reversible switching between active and inactive states using light.
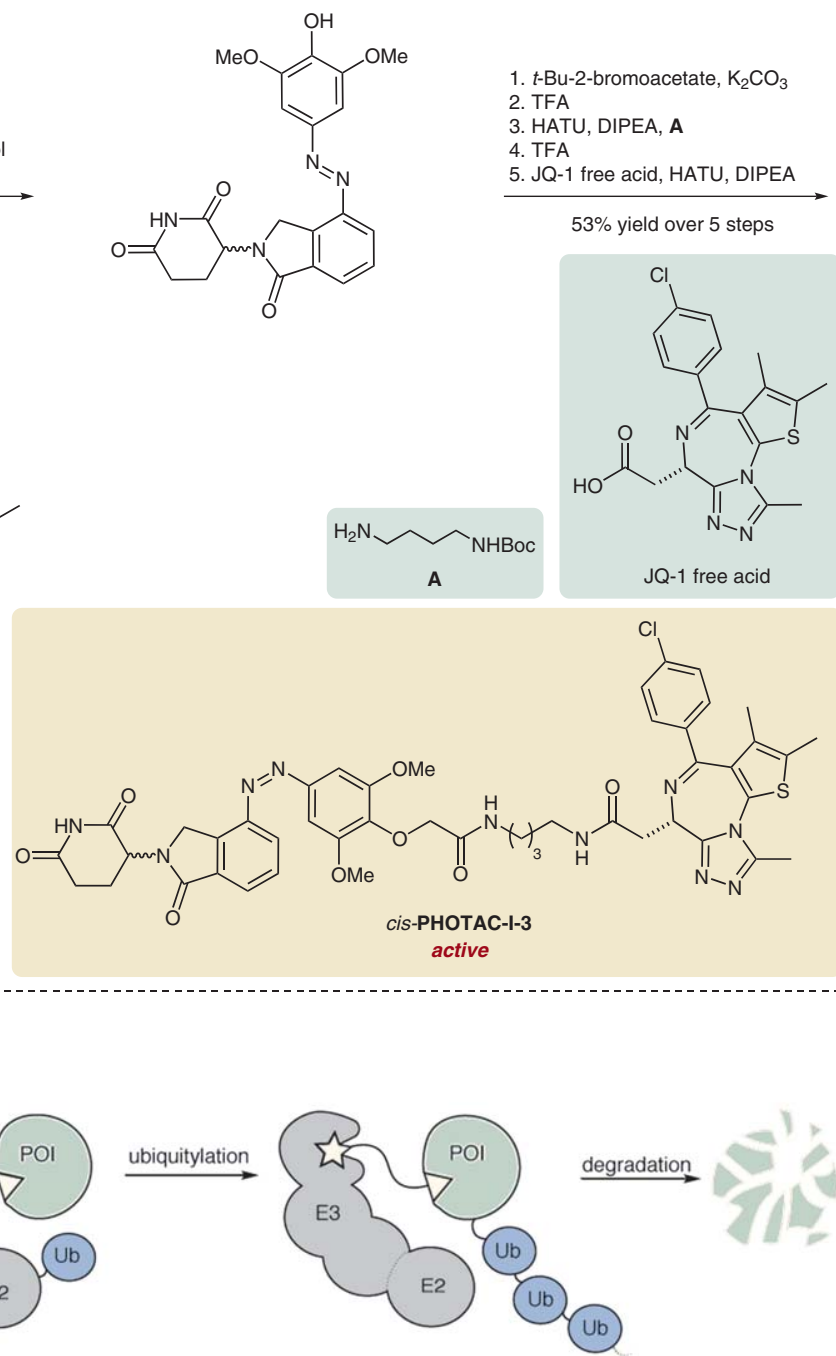

\section{Category}

Chemistry in

Medicine and

Biology

\section{Key words}

\section{PHOTACs}

photopharmacology

PROTACs

t-Bu-2-bromoacetate, $\mathrm{K}_{2} \mathrm{CO}_{3}$

2. TFA

, DIPEA, $\mathbf{A}$

5. JQ-1 free acid, HATU, DIPEA

$53 \%$ yield over 5 steps

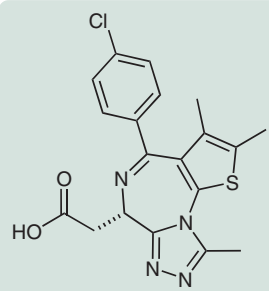

Comment: Based on a photoswitchable analog of the cereblon ligand thalidomide, this approach provides a general method to turn PROTACs into PHOTACs, which are active only upon irradiation. The authors use this strategy for the targeted degradation of BRD2/3/4 and FKBP12. 